\title{
Research on the Status Quo, Problems and Countermeasures of China's Tourism E-commerce Development under the Background of Internet
}

\author{
Siqi Li \\ Zhengzhou University Administrative Engineering College \\ \{f_author \}865591545@qq.com
}

Keywords: E-Tourism; current situation analysis; development strategy

\begin{abstract}
This thesis on China's E-Tourism research background, significance, research status at home, the framework, and related theoretical knowledge summed up, summarized the development stages of E-Tourism in china. Then, statement of current situation of the development of E-Tourism in China, through the using of the PEST macro-environment analysis, the favorable conditions of E-Tourism development and the existing problems are. It also puts forward some countermeasures to promote the rapid and healthy development of China's E-Tourism.
\end{abstract}

\section{Development Status of China's Tourism E-Commerce}

\subsection{Internet Scale}

China's Internet industry as a whole is becoming more standardized and valued, and the mobile Internet is driving the consumption model toward information sharing, equipment intelligence and scene diversification. In the mobile Internet, mobile payment has rapidly penetrated into the offline payment field, adding more payment scenarios and increasing the flow rate and flow of funds on the Internet. In 2016, the proportion of computer use, Internet use, and broadband access of enterprises increased compared with the previous year, and the electronic use of enterprises was basically popular. Especially in the field of information communication, human resources and financial management, Internet applications are particularly frequent, and $60 \%$ of enterprises have an information system. The "Internet + " traditional industry integration is accelerating. In the process of supply chain reform, enterprises are paying more and more attention to the full use of the Internet.

\subsection{Development Status of E-Commerce}

According to the "2015 China E-Commerce Market Data Monitoring Report" released by China E-Commerce Research Center, as of December 31, 2015, China's e-commerce transaction volume reached 18.3 trillion yuan, a year-on-year increase of $36.5 \%$, an increase of $5.2 \%$. The scale of online retail transactions reached 3.8 trillion yuan, a year-on-year increase of $35.7 \%$. The scale of online shopping transactions on the mobile side has increased tremendously, reaching 2.02 trillion 
yuan in 2015, up 117.4\% year-on-year. The number of users in the online retail industry reached 460 million, up 21\% year-on-year. In terms of employees, China's e-commerce enterprises directly employ more than 2.7 million people, and the number of indirect employment driven by e-commerce exceeds 20 million.

\subsection{Online Business Status of Tourist Attractions}

With the expansion of Internet applications, the promotion of the "Internet + " smart travel platform, the role of the Internet in tourism and related industries is growing. In 2015, the national high-star scenic spot Internet penetration rate reached 25.9\%. Mature Internet technology makes online sales a key link, and paperless services are more suitable for the needs of the times and more competitive. In terms of regions, the proportion of online sales of high-star scenic spots in East China reached $30.6 \%$, and the Internet penetration rate was the highest, which has a strong correlation with the popularity and application of the Internet and the economic level.(Cheng Yueming,2016)

\subsection{Online Tourism Development Status}

According to iResearch data, the scale of China's online travel market transactions in 2015 was 432.63 billion yuan, up 39.9\% from the previous year. It is expected to reach 542.09 billion in 2016 . It is expected that online vacation will account for $18.7 \%$ in the next year. Weekend tour, self-driving tour, outbound tour The market continues to be hot. Monitoring data shows that travel users have more traffic on the mobile side than on the PC side. In 2015, the average number of monthly visits to online mobile travel accounted for $64.6 \%$, a slight decrease compared with the previous year. With the increase of diversified tourism services and the emergence of new types of tourism services such as customized tourism, tourists will pay attention to the advantages and disadvantages of PC and mobile terminals when using these services.

\section{Review of Related Concepts and Theories}

\subsection{E-Commerce and Tourism E-Commerce}

E-commerce is an emerging economic form. Broad sense of e-commerce refers to the use of computer, Internet, telecommunications and other modern information technology for the business and corporate activities used, embarking on the track of networking, electronic and data. Narrow e-commerce refers to people using electronic means to conduct various commodity trading activities that span space constraints. The process is closely related to service value and currency exchange, and can use e-commerce to create direct economic value and bring profits to enterprises. The mall (platform), products, consumers, and logistics systems are the four components of e-commerce. Compared with traditional commodity trading, electronic tools are more convenient and faster to adapt to development. Advertising, online shopping, transaction management, online payment, and more and more social activities require the support of e-commerce.(Zhao Yuan,2012)

The exact concept of tourism e-commerce is still being explored. This paper defines the basic concept of tourism e-commerce as: tourism e-commerce refers to tourism marketing and service activities based on modern information technology, giving full play to the advantages of e-commerce, improving the traditional tourism business, processes and modules, thereby rapidly improving tourism services. Economic activities of quality and economic efficiency. It has the characteristics of virtualization, low cost, strong coordination, high integration, and easy to meet individual needs. Tourism e-commerce is an organic combination of e-commerce and tourism. The 
key is to integrate and optimize various functions of tourism products and services through modern information technology.(Luo Dan,2015)

\subsection{Tourism E-Commerce Transaction Mode}

There are three main trading modes of tourism e-commerce: one is the transaction mode between travel service providers (B2B), such as travel agencies booking air tickets, hotels, travel agents, sales routes, etc.; second, between travel service providers and consumers. The trading model (B2C), which is the protagonist of the tourism e-commerce transaction model. The target customers of the tourism industry are more dispersed. The tourism enterprises concentrate resources so that they can query information, book travel products, and overcome the information asymmetry caused by time and space restrictions. Third, the government agency directly deals with the tourist's transaction model (G2C). The competent department of tourism resources establishes a business platform for tourism products and services on the official website, and directly sells tickets or other tourism products to tourism consumers. There are also some smaller trading models, such as online travel companies' business model for government agencies (B2G), government marketing information through online travel service providers, and e-commerce between travel and personal travel providers (C2C) This model is mostly used for souvenirs, souvenirs, farmhouses and other transactions; tourists point to the trading model of tourism companies (C2B), consumers demand, travel companies to meet the travel needs of consumers through bidding.(Che Yuhang,2015)

\section{Past Analysis of China's Tourism E-Commerce Development}

This part uses the PEST analysis of the macro environment to explain the current development of China's tourism e-commerce from the perspective of strategic management through political (Politics), economy (Economy), society (Society) and technology (Technology). This is the target of the development of China's tourism e-commerce.

\subsection{Political Factors (Politics)}

The theme of the current era is peace and development. The pace of globalization and regional integration in the world is accelerating. The economic and cultural cooperation between many countries and regions is strengthened. The relatively stable international environment provides a good external environment for the development of the world tourism economy. surroundings. With the acceleration of industrialization and urbanization in China, during the 13th Five-Year Plan period, the Ministry of Industry and Information Technology and the Ministry of Commerce have also formulated a series of policy plans to improve China's informationization and promote the development of e-commerce. The "Internet +" program promotes industrial cooperation and transformation, and tourism e-commerce will usher in a good opportunity for strategic development.(He Xiang,2013)

\subsection{Economic Factors (Economy)}

In recent years, the income of urban and rural residents in China has steadily increased, and the distance from the goal of building a well-off society in an all-round way is closer. The work of getting rid of poverty has achieved remarkable results. In terms of household consumption levels, per capita consumption expenditures continue to rise, while the Engel coefficient, which accounts for the proportion of food consumption, is declining, indicating that people's willingness to consume is not only satisfied with food and clothing, but also a more exciting spiritual life. In terms 
of cultural and entertainment expenditures, both urban residents and rural residents are experiencing increasing consumer spending. The improvement of the economic form will have a positive effect on tourism.(Zhao Liping,2009)

\subsection{Social Factors (Society)}

The improvement of transportation facilities has greatly promoted people's desire for tourism. During the "Twelfth Five-Year Plan" period, the total mileage of China's railways, highways, aviation, inland waterways and other transportation continued to rise. In particular, the construction of high-speed railways is progressing rapidly, and the passenger traffic volume of railways is increasing, which means that the ticketing business of tourism e-commerce service providers has a wider profit margin. The average transportation distance of passengers increases, and the national transportation facilities can facilitate tourists to reach farther places and enjoy the pleasure of tourism.

In terms of culture and education, the education level of residents has increased significantly. The cultural quality has improved significantly, people's demand for high-quality spiritual life has also increased, and the willingness and demand for travel has increased. At the same time, the improvement of the cultural level can also transport high-level talents for tourism e-commerce, which is conducive to the development of the tourism industry.

\subsection{Technical Factors (Technology)}

The value of information is becoming more and more prominent. New technologies such as big data mining and cloud computing are moving from concept definition to practical application. Weibo, WeChat, and community forums have a variety of new media tools to enrich our lives and influence the pattern of tourism marketing. The advantages of lower cost and timeliness make the advertising marketing and channel expansion of tourism e-commerce more diverse. Tourism group purchase, Raiders search, the infinite change of business model, while expanding the space for tourism e-commerce, it also reminds merchants to maintain their advantages and promote innovation. (Yang Luming, Wu Ning, 2004)

\section{Analysis of China's Tourism E-Commerce Development and Countermeasures}

\subsection{Problems in the Development of China's Tourism E-Commerce}

\subsubsection{Regional Imbalance}

China has a vast territory, but the land and resources have brought about an imbalance in regional development. Tourism resources development in the south is generally more mature than in the north. In China's densely populated areas, tourism destinations, both in terms of income and passengers, are more abundant than those in the west, and are close to neighboring countries such as South Korea and Japan. The number of inbound and outbound tourists also has a clear advantage. In the vast territory of the central and western regions, due to inconvenient transportation, away from large and medium-sized cities, tourism resources are abundant, but it is difficult to get stronger development. The number of tourists visiting is small, and the enthusiasm of tourism innovation has been damped over time. The imbalance in regional tourism development.(Yan Yan,2014)

\subsubsection{Insufficient Market Supervision}

The chaotic pixels of the tourism market are deeply hated by consumers. Due to insufficient 
market supervision, the staff members' slack and even dereliction of duty, and the improper marketing methods of tour operators, many consumers' rights and interests were violated during the travel process. However, the relevant departments are often exposed in the event of chaos, and the network has been fermented before the treatment, but there is no pre-warning, anti-micro-duration. Whether it is the traditional tourism in the past or the leading mode of online travel in the future, the market chaos is a stubborn disease. If you do not deal with it, it will only become more chaotic and hinder the advancement of the tourism industry.(Liu Qing,2016)

\subsubsection{Networking Needs To Be Improved}

The development of tourism e-commerce must begin with the network construction of tourism products and services.

For traditional travel agencies and scenic management departments, the era of adapting to networking is particularly important. Many travel agencies ignore the utility of the Internet. Managers do not fully understand the competitiveness of networking and informationization, and are unwilling to spend too much cost on network construction. The network level of most travel agencies is very low, and the information construction of information consultation, reservation processing, resource analysis, and customer management are not perfect. Therefore, the workflow is cumbersome, the repetition rate is high, and the cost is high.(Xue Qihu,2010)

\subsubsection{Secure Payment Credit System Needs To Be Improved}

The most direct manifestation of the trust relationship between the travel e-commerce service provider and the consumer is whether the consumer recognizes the security of the service provider's online payment system. The credit system is a common problem of the whole society. However, China's current laws and regulations on the online payment and credit system are not perfect, and the investigation and punishment of credit fraud is insufficient. Online payment has potential safety hazards. On the surface, it seems that the tourism e-commerce is booming, but because of the small flow of funds, it is strong and lacks core competitiveness, which causes the function of the entire tourism e-commerce system to derail and operate poorly.

\subsubsection{Lack Of High-Quality Talents}

The lack of high-quality talent in the tourism industry is a long-term problem. Among the staff currently engaged in the tourism industry, some of them have low level of professional quality and do not have the criteria to carefully serve tourists. On the other hand, travel e-commerce requires a lot of high-end technical support. There are not many college graduates in tourism-related majors and e-commerce majors, but there are few colleges and universities that combine tourism and e-commerce. The output of compound talents is in short supply.

\subsection{Feasibility Countermeasures for the Development of China's Tourism E-commerce}

\subsubsection{Play the Government's Powers and Responsibilities and Build an External Environment}

In the development of tourism e-commerce, the role of government departments is crucial, and a good external environment must be built under the leadership of the government.

First, the government should support the development of tourism e-commerce in a targeted manner. Tourism travel e-commerce is an emerging service industry with highly integrated information. The technology, capital and resources that need to be used are widely involved. In the construction of tourism e-commerce national information platform and database, government 
departments should give policy support, such as Government-enterprise cooperation integrates planning of regional tourism resources, and appropriate local tourism modules and tourist scenic links are added to the government affairs website to facilitate tourists to obtain information.

Second, the government should lead the promotion of networking and informationization. Internet coverage has greatly affected the development of tourism e-commerce and related industries. The government should increase capital investment, improve network infrastructure, and increase promotion of areas with low Internet coverage and weak information base, and encourage tourism service enterprises. Take the road of electronic operation, reduce costs and increase profits.

\subsubsection{Improve Laws and Regulations and Strengthen Market Management}

The development of any industry must follow the rules of the market. China's e-commerce started late, and we want to make tourism e-commerce play a role in the future. All relevant entities must work together and work together. Promote the synergy of all parties, strengthen supervision and management, improve laws and regulations, and rectify the chaos in the tourism market.

The legislative and judicial departments must lead the acceleration of the establishment of relevant laws and regulations on e-commerce, clarify the safeguard clauses for tourism e-commerce, and regulate the legal operation of online travel service providers through legislation, eliminate false information, and maximize the protection of consumers' legitimate rights and interests. The national tourism supervision service platform, new media tools, and travel complaints are all supervised tools that can be used reasonably, so that the eyes of the people can become a sword to kill chaos.

\subsubsection{Balance Regional Gaps and Enhance the Impact of Scenic Spots}

The impact of regional imbalances is multifaceted and tourism will be affected. As far as China's tourism resources are concerned, the eastern region is obviously superior to the western region. Coupled with infrastructure factors such as traffic conditions, it is easy to cause polarization. Therefore, in-depth development of resources in underdeveloped tourism areas and promotion of tourism e-commerce development must strengthen road traffic infrastructure construction and improve passenger carrying capacity. Within some large-scale scenic spots with natural scenery, restricting the passage of private cars and implementing bus ferry in the scenic spot can greatly alleviate the traffic conditions inside the scenic spot. For example, the Jiuzhaigou scenic spot is a good example. The restricted line of private cars avoids chaos and chaos, ensures the smoothness of the scenic roads, and enhances the user satisfaction of tourists.

How to improve the characteristic influence of the scenic spot is also a problem that tourism managers need to think about. Tourist attractions need to convey not only the sensory experience for tourists, but also the potential for exploration. For example, the 3D postcard of the Shaanxi History Museum uses the VR technology to present the precious cultural relics in the collection. The traditional tourism products are upgraded in the direction of networking, which will bring tourists an unprecedented and enjoyable experience. (Li Wei, 2015)

\subsubsection{Strengthen Website Construction to Ensure Transaction Security}

Whether it is an online travel service provider or a tourist attraction, the website is the most important channel for external information dissemination. For online travel service providers, it is especially important to enhance the interaction of the website. For the website construction of tourist attractions, it is necessary to highlight the unique characteristics of the scenic spots, optimize the website structure, give the viewers a high-quality sensory experience, and avoid excessive white space and advertising flooding. Well-known scenic spots should pay special attention to the 
internationalization of the website and the rapid foreign language conversion function, which can bring great convenience to international tourists.

Tourism e-commerce needs to use the convenience and efficiency of the Internet, but also to guard against the security of funds flowing online. Banking systems, third-party payment platforms, etc. need to strengthen the technical level of online payment. On this basis, banks and financial institutions should also establish cooperative relationships with tourism e-commerce companies and tourist attractions to ensure the high security of online payment technology applications.

\subsubsection{Cultivate Compound Talents and Improve the Quality of Personnel}

The lack of tourism e-commerce composite talents is in urgent need of improvement. National agencies such as the National Tourism Administration, the Ministry of Education, and the Ministry of Industry and Information Technology shall cooperate in cooperation, open relevant disciplines in higher education institutions, focus on scientific research, and create a good learning environment. Tourism e-commerce companies can also increase cooperation with colleges and universities, provide corresponding visit experience and internship opportunities during the students' study, familiarize students with the subject knowledge applied in tourism e-commerce, and gain a deeper understanding of the nature and trends of the industry. aspect.

For in-service tourism practitioners, the competent department should strengthen the cultivation of its own quality and work ability. Establish a sound work performance mechanism, the ability to go, the level of the person, the mediocrity, encourage the enthusiasm of the staff, regularly improve the training of employees, explore the potential of excellent employees, and better complete the work. Leaders and relevant module staff should regularly study tourism e-commerce knowledge and skills, cultivate awareness of e-commerce and information, and strengthen the operational capabilities of tourism e-commerce.

\section{Conclusion}

In recent years, China's e-commerce economy has developed vigorously, in line with the "Internet +" program, and the promotion of e-commerce has brought many favorable conditions for the development of tourism. With the continuous deepening of the use of the Internet, China's tourism transformation has followed. This paper, through reference to data research, reports and surveys of relevant national institutions, uses data, tables and charts to illustrate the current situation of China's tourism e-commerce. Using PEST analysis and simple case narrative, it explains China's tourism e-commerce from four aspects. Favorable macro environmental factors for development. Generally speaking, the development of tourism e-commerce economy is on a stable and healthy road. However, due to various reasons such as management system, market rules and industrial structure, there are still many problems in China's tourism e-commerce. Finally, this paper draws on the research results of many experts and scholars, and closely combines the problems existing in China's tourism e-commerce at the present stage, and exploratively proposes feasible countermeasures for each problem, that is, to exert the government's powers and responsibilities to build the external environment and improve laws and regulations. In order to strengthen market supervision, enhance the influence of scenic spots to narrow the development distance of the region, strengthen the construction of tourism e-commerce website and ensure the security of online payment, and focus on cultivating composite talents for tourism e-commerce, and improve the overall quality of industry staff.

Due to the numerous research directions of tourism e-commerce, there are certain errors in collecting and using data. In addition, the author's cognition and ability of tourism e-commerce is not sufficient, the research level is limited, and the suggestions for the problems existing in the 
current stage of tourism e-commerce are subjective. Therefore, research on the development of China's tourism e-commerce needs to be deepened and improved.

\section{References}

[1] Cheng Yueming. Research on the Impact of Tourism E-commerce on Tourism Development from the Perspective of "Internet +"[J]. Coastal Enterprises and Technology, 2016, (05): 36-39

[2] Che Yuhang. Research and Analysis of Yunnan Tourism E-commerce Platform [D]. Yunnan: Yunnan University, 2015. 3-4

[3] China Internet Network Information Center. The 39th Statistical Report on the Development of China's Internet Network [EB/OL]. Http://www.cnnic.cn/gywm/xwzx/rdxw/20172017/201701/t20170122_66448.htm.

[4] China National Tourism Administration. 2015 China Tourism Statistics Bulletin [EB/OL]. Http://www.cnta.gov.cn/zwgk/lysj/201610/t20161018_786774.shtml.

[5] E-Business for Tourism. Practical Guidelines for Destinations and Business [M]. UNWTO Publications: World Tourism Organization Business Council, 2002.

[6] He Xiang. Research on the development of e-commerce in China's tourism industry [D]. Beijing: Capital University of Economics and Business, 2013. 2-6

[7] Li Wei, Wei Xiang. "Internet + Tourism": A New Observation of Online Tourism [M]. Beijing: China Economic Publishing House, 2015. 174-180

[8] Liu Qing. Feasibility Analysis of Scenic Spot Development Strategy under Tourism Mobile E-commerce [J]. China Market, 2016, 224-225

[9] Luo Dan. Research on the Development of Tourism E-commerce in Sichuan—Based on the Comparison of Typical Scenic Spots in Sichuan and China [D]. Sichuan: Xihua University, 2015. 3-4

[10] Ou Haiying. Case Analysis of Tourism E-commerce Enterprises [M]. Beijing: Tourism Education Press, 2015. 152-160

[11] Xue Qihu. Innovation of business model of online tourism enterprises based on e-commerce environment [D]. Shandong: Shandong University, 2010. 22-26

[12] Yan Yan. Application of e-commerce in Shilin Tourism [D]. Yunnan: Yunnan University, 2014. 8

[13] Yang Luming, Wu Ning. Tourism E-commerce [M]. Beijing: Mechanical Industry Press, 2004.

[14] Zhao Liping. Introduction to E-Commerce [M]. Shanghai: Fudan University Press, 2009. 13-15 